\title{
Laser Ablation-Inductively Coupled Plasma Mass Spectrometry for the Characterization of Pigments in Prehistoric Rock Art
}

\author{
Martin Resano,*,† Esperanza García-Ruiz,† Ramiro Alloza,‡ Maria P. Marzo,‡ Peter Vandenabeele,\$ and \\ Frank Vanhaecke $\$$
}

Department of Analytical Chemistry, Faculty of Sciences, University of Zaragoza, Pedro Cerbuna 12, Zaragoza, Spain, E-50009, Laboratory of Research and Analysis of Cultural Heritage Materials, Aragón Government, Av. San José 5, Cuarte de Huerva, Zaragoza, Spain, and Department of Analytical Chemistry, Ghent University, Proeftuinstraat 86, Ghent, Belgium, B-9000

In this work, several red-colored paintings of post-Paleolithic schematic style found in 10 different shelters in the vicinity of the Vero River (Huesca) were sampled and subjected to analysis by means of scanning electron microscopy-energy-dispersive X-ray spectrometry (SEMEDX), Raman spectroscopy, and laser ablation-inductively coupled plasma mass spectrometry (LA-ICPMS). The goal of this research was to obtain meaningful information on the samples composition, in order to establish differences or similarities among them. The combined use of these techniques proved beneficial, as Raman data permitted structural information on the compounds present (hematite was identified as the main pigment, whereas calcite and gypsum are the main components of the substrate layer, as well as of the accretions that covered the pigments) to be obtained, while the quantitative values obtained by SEM were suitable for the use of $\mathrm{Ca}$ as internal reference during LA-ICPMS analysis. However, it was this latter technique that provided the most relevant data for fingerprinting purposes. The potential of this technique for obtaining spatially resolved information allowed the multielement quantitative analysis of the pigment layer, in spite of the presence of superficial accretions. The sensitivity of the technique permitted the determination of more than 40 elements present in a wide concentration range (from microgram per gram to $10 \%$ level) with minimum sample consumption (approximately $900 \mathrm{ng}$ for each sample, corresponding to five replicates). Finally, in order to establish significant differences, only those elements showing a high correlation with Fe (As, $\mathrm{Co}, \mathrm{Mo}, \mathrm{Sb}, \mathrm{Tl}$, and $\mathrm{Zr}$, in this case) were selected, as it is expected that these were truly present in the original pigment, while others could have migrated into the pigment layer throughout time. By using this information, it seems feasible to discriminate between various paint pots, as demonstrated for the samples under investigation.

\footnotetext{
* Corresponding author. E-mail:mresano@unizar.es.

$\dagger$ University of Zaragoza.

₹ Laboratory of Research and Analysis of Cultural Heritage Materials, Aragón Government.

$\S$ Ghent University.
}

At the end of the Ice Age, the great herds that had provided sustenance for the Paleolithic hunters disappeared from France and Spain. In the large forest areas that flourished owing to the warmer climate, groups of deer and related species lived. These animals were fast and elusive and, thus, much harder to hunt. As a consequence, man had to modify his hunting techniques, as well as forage for the seeds and fruits that the forest provided or the fish that were available in rivers or on the coast. Cooperation was essential, and this change was reflected in the art of this postPaleolithic period. ${ }^{1}$

Bands of such hunter-gatherers left a record of their activities in shelters scattered throughout the Iberian Peninsula, among other regions. The differences with Paleolithic paintings are evident, as a simpler silhouette technique emerges. Moreover, the new paintings seem to have a clear narrative meaning, featuring a higher proportion of hominine figures. ${ }^{2}$ Investigation of these paintings can provide relevant hints about the technological level as well as about the social structure of these early societies. In this context, the physicochemical characterization of the pigments present in these paintings by means of suitable analytical techniques is needed.

Most of the research carried out to date has focused on the use of techniques capable of providing molecular and/or structural information, such as X-ray diffraction (XRD) or the increasingly popular Raman spectroscopy, ${ }^{3-11}$ in combination with the mor-

(1) Western Painting. Encyclopaedia Britannica [Online]. http://www.britannica.com/eb/article-69467 (accessed May 30, 2007).

(2) Utrilla, P. El Arte Rupestre en Aragón; CAI 100 Collection, no. 56; Caja de Ahorros de la Inmaculada: Zaragoza, Spain, 2000.

(3) Vandenabeele, P.; Edwards, H. G. M.; Moens, L. Chem. Rev. 2007, 107, 675-686.

(4) Edwards, H. G. M.; Drummond, L.; Russ, J. J. Raman Spectrosc. 1999, 30, $421-428$.

(5) Hernanz, A.; Gavira-Vallejo, J. M.; Ruiz-López, J. F. J. Optoelectron. Adv. Mater. 2007, 9, 512-521.

(6) Hernanz, A.; Gavira-Vallejo, J. M.; Ruiz-López, J. F. J. Raman Spectrosc. 2006, 37, 1054-1062.

(7) Edwards, H. G. M.; Newton, E. M.; Russ, J. J. Mol. Struct. 2000, 550-551, 245-256.

(8) Smith, D. C.; Bouchard, M.; Lorblanchet, M. J. Raman Spectrosc. 1999 , 30, 347-354.

(9) Guineau, B.; Lorblanchet, M.; Gratuze, B.; Dulin, L.; Roger, P.; Akrich, R.; Muller, F. Archaeometry 2001, 43, 211-225.

(10) Hernanz, A.; Mas, M.; Gavilán, B.; Hernández, B. J. Raman Spectrosc. 2006 , 37, 492-497.

Analytical Chemistry, Vol. 79, No. 23, December 1, 20078947 
phological inspection of the surfaces by optical microscopy, transmission electron microscopy (TEM), or scanning electron microscopy (SEM). ${ }^{12,13}$ Thanks to these works, the most widely used prehistoric pigments have been identified (hematite for redbrownish colors and manganese oxides/hydroxides or charcoal for black coloration), and there is strong evidence suggesting that these prehistoric artists already knew how to transform goethite (yellow) into hematite of the desired coloration by means of heating. ${ }^{14,15}$ It is believed that these pigments were mixed with extenders (e.g., quartz, talc, clay) and with a binder (e.g., water or organic substances such as animal fat, resin, or egg), to favor its deposition on the rock. ${ }^{13,16-19}$

The use of elemental techniques in order to investigate prehistoric pigments has been much more scarce. Energydispersive X-ray spectrometry (EDX) results have been reported sometimes, although this technique suffers from its limited sensitivity. 5,9,13,20 Other techniques with more potential for trace analysis, such as proton induced X-ray emission spectrometry (PIXE) $)^{13,21}$ and neutron activation analysis (NAA) ${ }^{9}$ have been occasionally deployed. In general, the use of these elemental techniques has been limited to confirm the identity of the main pigments, and no systematic effort was done to use these techniques for fingerprinting purposes.

Certainly, the analysis of these kinds of samples is not an easy task. On the one hand, the amount of sample available for analysis is always minimal. Owing to their high cultural value, these paintings are protected by the authorities and it is mandatory that only nonperceptible damage will be caused. On the other hand, in many cases the samples have been exposed in open areas for thousands of years. As a result of this, most paintings are covered by accretions, and it can be anticipated that phenomena of infiltration/reaction of the pigment layer with other layers (substrate and covering layer) may have occurred, making it difficult to obtain reliable analytical information on the original pigment only. ${ }^{8}$

For these reasons, analysis of these materials should be carried out using techniques that offer a high sensitivity, even when sampling at submicrogram levels, multielement possibilities, and particularly, depth-profiling potential with sufficient resolution. Laser ablation-inductively coupled plasma mass spectrometry (LAICPMS) seems capable of fulfilling these requirements, ${ }^{22-26}$ but to the best of the authors' knowledge, no work to date has

(11) Ospitali, F.; Smith, D. C.; Lorblanchet, M. J. Raman Spectrosc. 2006, 37, 1063-1071.

(12) Rowe, M. W. In Rock Art Research; Whitley, D. S., Ed.; AltaMira Press: Lanham, MD, 2001.

(13) Chalmin, E.; Menu, M.; Vignaud, C. Meas. Sci. Technol. 2003, 14, 15901597.

(14) Pomiès, M. P.; Menu, M.; Vignaud, C. J. Eur. Ceram. Soc. 1999, 19, 16051614.

(15) Pomiès, M. P.; Menu, M.; Vignaud, C. Archaeometry 1999, 41, 275-285

(16) Kritzon, C. Bull. Primitive Technol. 2002, 24. (Available online at http:// www.primitiveways.com/paint_a_mammoth.html, accessed October 21, 2007.)

(17) Barnett, J. R.; Miller, S.; Pearce, E. Opt. Laser Technol. 2006, 38, 445-453.

(18) Clottes, J.; Menu, M.; Walter, P. Rock Art Res. 1990, 7, 21-26.

(19) Williamson, B. S. J. Archaeol. Sci. 2000, 27, 755-762.

(20) Garate, D.; Laval, E.; Menu, M. L'anthropologie 2004, 108, 251-289.

(21) Chalmin, E.; Menu, M.; Pomiès, M. P.; Vignaud, C.; Aujoulat, N.; Geneste, J. M. L'anthropologie 2004, 108, 571-592.

(22) Russo, R. E.; Mao, X.; Liu, H.; Gonzalez, J.; Mao, S. S. Talanta 2002, 57, $425-451$.

(23) Günther, D.; Hattendorf, B. Trends Anal. Chem. 2005, 24, 255-265. reported on the use of this technique for the investigation of prehistoric paintings.

In this work, samples from 10 different shelters located in the vicinity of the Vero River (Sierra Guara, Huesca, Spain), approximately $50 \mathrm{~km}$ south of the Pyrenees, have been taken. The collection of art rock paintings found in this area was designated by UNESCO as a World Heritage in 1998. Only red figures belonging to the same artistic style (post-Paleolithic schematic style, which is supposed to date from the fourth-third millennium B.C.) ${ }^{27}$ were sampled. The maximum separation between these shelters is $58 \mathrm{~km}$, and most of them are within $10 \mathrm{~km}$ distance, so it is interesting to investigate whether the shelters could have been painted by the same artists or if there are significant differences among them. Elemental information as obtained via LA-ICPMS analysis of the pigments may, in combination with SEM and Raman data, shed some light on this point.

\section{EXPERIMENTAL SECTION}

Instrumentation. A GeoLas $193 \mathrm{~nm}$ ArF excimer-based LA system (MicroLas, Germany) was used for sample introduction. In this device, the UV laser beam coming from the Compex102 laser unit (LambdaPhysik, Germany) undergoes homogenization, ${ }^{28}$ enabling flat-bottomed and straight-walled craters to be obtained. The ablation cell was coupled to the ICP torch via a 3 mm i.d. Tygon tubing. A mixture of Ar and He was used for carrier purposes. The ablation cell is mounted on a stage that allows software-controlled translation in all three spatial directions. The cell is monitored by a camera in such a way that it is possible to select the exact location for ablation. All measurements were performed using a Perkin-Elmer Sciex DRCplus quadrupole-based ICP mass spectrometer (Canada), operated in vented mode.

A JEOL (Japan) JSM-6360LV SEM was used for evaluation of the samples and the craters produced by LA-ICPMS, as well as for the quantitative determination of the components present at high levels in the pigments (higher than 0.1\%). The SEM was equipped with a system for energy-dispersive X-ray analysis (INCA Oxford Instruments, England), with ZAF correction.

Dispersive Raman spectroscopy has been performed using a Renishaw (United Kingdom) System 1000 spectrometer, operating at a laser wavelength of $785 \mathrm{~nm}$. This instrument is equipped with a $50 \mathrm{~mW}$ laser source $(<5 \mathrm{~mW}$ at the sample). The spectrometer consists of a 1200 grooves $\mathrm{mm}^{-1}$ diffractive grating and a Peltiercooled CCD detector, providing a spectral resolution of $<1 \mathrm{~cm}^{-1}$.

Samples. Several painting samples (two or three per shelter) from 10 shelters across the Vero River were taken. The archaeological denominations of these shelters are Barfaluy (BAR II), Coveta de l'Engardaixo (ENG), Gallinero I (GAL I), Gallinero II (GAL II), Gallinero III (GAL III), Mallata B (MALB), Mallata C (MALC), Tozal de Mallata (MALA), La Raja E (RAES), and Cueva de Regacens (REG).

(24) Barnes, J. H.; Schilling, G. D.; Hieftje, G. M.; Sperline, R. P.; Bonner Denton, M.; Barinaga, C. J.; Koppenaal, D. W. J. Am. Soc. Mass Spectrom. 2004, 15, 769-776.

(25) Stadlbauer, C.; Prohaska, T.; Reiter, C.; Knaus, A.; Stingeder, G. Anal. Bioanal. Chem. 2005, 383, 500-508.

(26) Pisonero, J.; Koch, J.; Wälle, M.; Hartung, W.; Spencer, N. D.; Günther, D. Anal. Chem. 2007, 79, 2325-2333.

(27) Bradley, R.; Chippindale, C.; Helskog, K. In Rock Art Research; Whitley, D. S., Ed.; AltaMira Press: Lanham, MD, 2001; p 495.

(28) Günther, D.; Frischknecht, R.; Heinrich, C. A.; Kahlert, H.-J. J. Anal. At. Spectrom. 1997, 12, 939-944. 
(A)

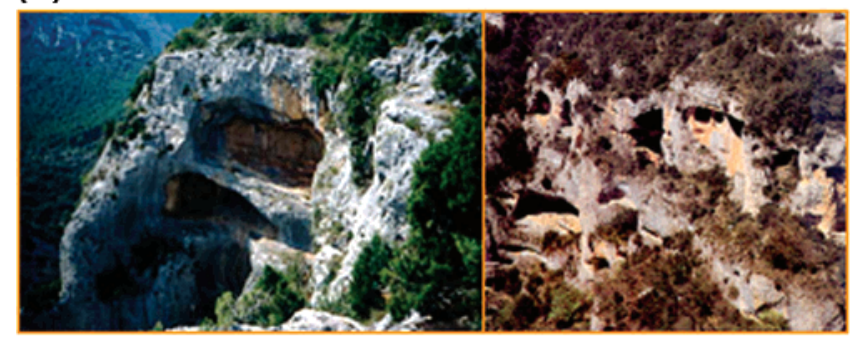

(B)

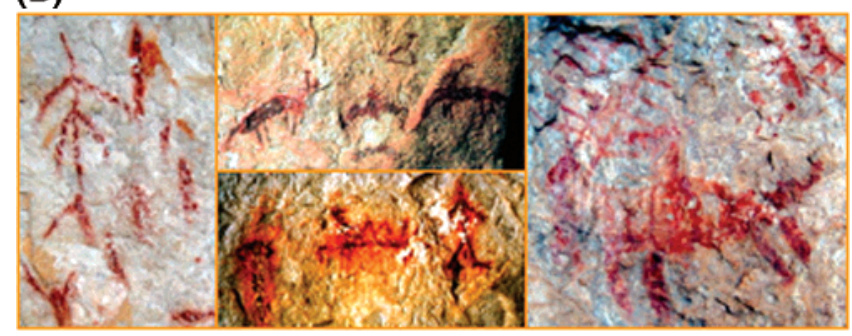

(C)

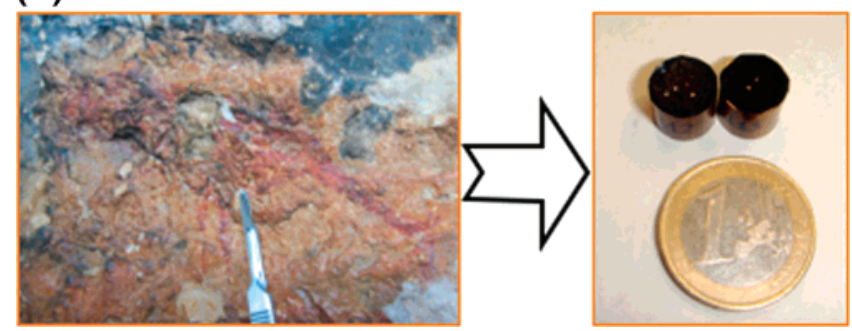

Figure 1. (A) Mallata B (MALB) and Gallinero (GALI, GALII, GALIII) shelters, in the Rio Vero canyon. (B) Some typical examples of anthropomorphic and deerlike figures of schematic style found in Barfaluy (BAR II), Mallata B (MALB), and Regacens (REG) shelters. (C) Sampling of submillimeter pieces of red pigment from a prehistoric painting and samples after deposition on a substrate, suitable for analysis by means of SEM, Raman spectroscopy, and LA-ICPMS.

Samples were collected using sterile surgical blades, and extreme care was taken to minimize the damage inflicted to the paintings. All samples were of submillimeter size, as illustrated in Figure 1. Moreover, those parts of the paintings in which previous environmental or human damage was apparent were preferably chosen for sampling, and the contour of the figures was always preserved. Photographs of the area before and after sampling were taken. The samples were stored in $1 \mathrm{~mL}$ Eppendorf tubes. Substrate samples were also collected for comparison. Finally, all samples were deposited in carbon adhesive tape and mounted onto metallic substrates, suitable for SEM, Raman, and LA-ICPMS examination.

Procedure for LA-ICPMS Analysis of the Pigments. The parameters used during the analysis of the pigments using LAICPMS are presented in Table 1. In order to obtain representative values, five sampling positions were selected across the surface for every pigment, whenever possible (on occasions, it was only feasible to carry out three replicates owing to the small sample size). When processing these data, as described below, median values (instead of average values) of all the replicates carried out were calculated, in order to minimize the possible influence of outliers. ${ }^{29-31}$

The laser was always focused on red-colored areas (hematite pigments). Each ablation consisted of 600 laser pulses. In every
Table 1. Instrumental Operating Conditions and Data Acquisition Parameters for the LA-ICPMS

\section{Measurements}

$\begin{array}{ll} & \text { GeoLas Laser Ablation System } \\ \text { output energy } & \sim 1.7 \mathrm{~mJ} \text { on sample surface } \\ \text { repetition rate } & 20 \mathrm{~Hz} \\ \text { beam diameter } & 60 \mu \mathrm{m} \\ \text { number of pulses per replicate } & 600 \\ \text { cell volume } & \approx 30 \mathrm{~cm}^{3}\end{array}$

\begin{tabular}{ll}
\multicolumn{2}{c}{ Perkin-Elmer Sciex DRCplus ICP Mass Spectrometer } \\
rf power & $1200 \mathrm{~W}$ \\
Ar plasma/auxiliary flow rates & $17 / 1.2 \mathrm{~L} \mathrm{~min}^{-1}$ \\
carrier gas flow rate & $1.1(\mathrm{Ar})+0.4(\mathrm{He}) \mathrm{L} \mathrm{min}^{-1}$ \\
sampling cone and skimmer & $\mathrm{Pt}$ \\
lens voltage & $6.25 \mathrm{~V}$
\end{tabular}

Data acquisiton parameters

scanning mode peak hopping

dwell time per acquisition point $10 \mathrm{~ms}$

number of sweeps per reading 1

detector mode

nuclides monitored

dual (pulse counting and analog)

${ }^{7} \mathrm{Li},{ }^{9} \mathrm{Be},{ }^{11} \mathrm{~B},{ }^{13} \mathrm{C},{ }^{23} \mathrm{Na},{ }^{25} \mathrm{Mg},{ }^{27} \mathrm{Al}$, ${ }^{29} \mathrm{Si},{ }^{31} \mathrm{P},{ }^{34} \mathrm{~S},{ }^{35} \mathrm{Cl},{ }^{39} \mathrm{~K},{ }^{44} \mathrm{Ca},{ }^{45} \mathrm{Sc},{ }^{49} \mathrm{Ti}$, ${ }^{51} \mathrm{~V},{ }^{53} \mathrm{Cr},{ }^{55} \mathrm{Mn},{ }^{57} \mathrm{Fe},{ }^{59} \mathrm{Co},{ }^{60} \mathrm{Ni},{ }^{65} \mathrm{Cu}$, ${ }^{68} \mathrm{Zn},{ }^{69} \mathrm{Ga},{ }^{72} \mathrm{Ge},{ }^{75} \mathrm{As},{ }^{78} \mathrm{Se},{ }^{85} \mathrm{Rb},{ }^{88} \mathrm{Sr}$,

${ }^{89} \mathrm{Y},{ }^{90} \mathrm{Zr}$, ${ }^{93} \mathrm{Nb},{ }^{95} \mathrm{Mo},{ }^{101} \mathrm{Ru},{ }^{103} \mathrm{Rh}$,

${ }^{105 \mathrm{Pd},}{ }^{107} \mathrm{Ag},{ }^{111} \mathrm{Cd},{ }^{115} \mathrm{In},{ }^{118} \mathrm{Sn},{ }^{121} \mathrm{Sb}$ ${ }^{128} \mathrm{Te},{ }^{133} \mathrm{Cs}$, ${ }^{138} \mathrm{Ba},{ }^{139} \mathrm{La},{ }^{178} \mathrm{Hf},{ }^{181} \mathrm{Ta}$,

${ }^{182 \mathrm{~W}},{ }^{185} \mathrm{Re},{ }^{189} \mathrm{Os}$ s, ${ }^{193} \mathrm{Ir},{ }^{195} \mathrm{Pt},{ }^{197} \mathrm{Au}$,

${ }^{202} \mathrm{Hg},{ }^{205} \mathrm{Tl},{ }^{208} \mathrm{~Pb},{ }^{209} \mathrm{Bi}$

case, a transient signal was obtained. The zone of maximum $\mathrm{Fe}$ signal (consisting of those points that deviate less than $15 \%$ from the maximum signal intensity value for ${ }^{57} \mathrm{Fe}^{+}$) was considered to correspond with ablation of the pigment layer, and only that portion of the data was selected for quantification, as shown in Figure 2A. The signal from the ${ }^{44} \mathrm{Ca}^{+}$nuclide was used as internal reference, and NIST standard reference materials 610 and 612 (glass) were used for calibration. Moreover, for the final comparison of the results described in the Results and Discussion, LA-ICPMS Analysis of the Pigments and Comparison of the Different Shelters section, analyte concentrations per $1 \%$ of Fe were calculated, since, in this way, it is possible to minimize differences owing to the different amount of pigment present in every sample.

Procedure for Validation of LA-ICPMS Values. Validation of results was carried out by preparation of a homemade paint sample, spiked with known amounts of some elements. For this purpose, known amounts of $\mathrm{Al}, \mathrm{Ca}, \mathrm{Co}, \mathrm{Mn}, \mathrm{Fe}, \mathrm{Sn}$, and $\mathrm{Pb}$ salts were ground and mixed in an agate mortar for $3 \mathrm{~min}$ at $300 \mathrm{rpm}$. An amount of 14.0112 grams of that mixture was weighed, and 4 $\mathrm{mL}$ of a $1 \mathrm{~g} \mathrm{~L}^{-1} \mathrm{Ti}$ solution was added. In this way, a paste that could be applied onto a rock was obtained. Thus, a substrate rock was painted and subsequently dried during $48 \mathrm{~h}$ in an oven at 40 ${ }^{\circ} \mathrm{C}$, prior to LA-ICPMS analysis of the resulting sample. The conditions used for this analysis were the same used for the real pigment samples, described in Table 1, except for the list of isotopes monitored, which was limited in this case to ${ }^{27} \mathrm{Al},{ }^{44} \mathrm{Ca}$,

(29) Belarra, M. A.; Resano, M.; Castillo, J. R. J. Anal. At. Spectrom. 1999, 14, $547-552$.

(30) Belarra, M. A.; Resano, M.; Vanhaecke, F.; Moens, L. Trends Anal. Chem. 2002, 21, 828-839.

(31) Resano, M.; Pérez-Arantegui, J.; Garcia-Ruiz, E.; Vanhaecke, F. J. Anal. At. Spectrom. 2005, 20, 508-514. 

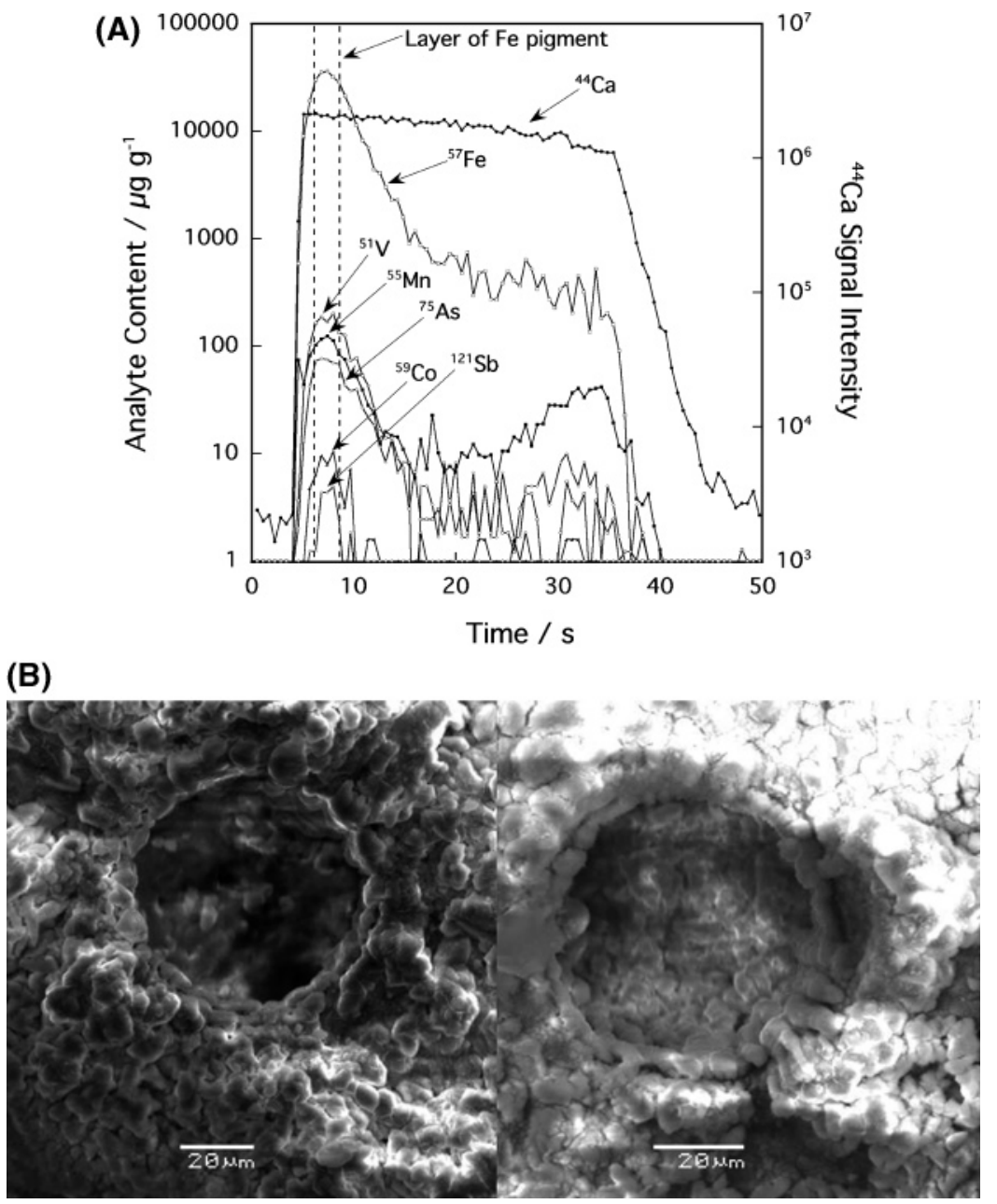

Figure 2. (A) Time-resolved signal obtained for a few of the elements monitored after LA-ICPMS analysis of sample BAR II-3 and the subsequent transformation of the signal intensities into analyte contents, using a calibration curve constructed with NIST 610 and 612 glasses and the signal of ${ }^{44} \mathrm{Ca}$ as internal reference. The original signal intensity profile for ${ }^{44} \mathrm{Ca}$ is also shown. (B) SEM image of the craters produced upon laser ablation (600 pulses) of the pigments. The crystalline structure surrounding the craters mainly consists of $\mathrm{CaCO}_{3}$.

${ }^{47} \mathrm{Ti},{ }^{49} \mathrm{Ti},{ }^{55} \mathrm{Mn},{ }^{57} \mathrm{Fe},{ }^{59} \mathrm{Co},{ }^{118} \mathrm{Sn},{ }^{120} \mathrm{Sn}$, and ${ }^{208} \mathrm{~Pb}$. The signal from ${ }^{44} \mathrm{Ca}$ was used as internal reference, and NIST SRM 610 and 612 were used as standards for calibration.

Alternatively, three separate portions of the paste were dried in a similar way, weighed (approximately $50 \mathrm{mg}$ each portion), and digested in a microwave oven with aqua regia. The resulting solutions were analyzed by pneumatic nebulization (PN)-ICPMS.

Procedure for the Microcharacterization of the Pigments by SEM-EDX. The acceleration voltage applied was $20 \mathrm{kV}$, with a $0.5 \mathrm{nA}$ current probe. Bulk analyses were accomplished by scanning a relatively large area $(\times 2000$ or $\times 4000$ magnification) of the pigment area and by acquiring data from 5 or 10 different points. The observation of the surface characteristics and the quantitative analysis were carried out directly on the external side of the samples in back-scattered electron (BSE) mode. Calibration was carried out using a $\mathrm{CaCO}_{3}$ standard (>99\% purity).

Procedure for the Microcharacterization of the Pigments by Raman Spectroscopy. Raman excitation was performed with a $785 \mathrm{~nm}$ diode laser. The laser spot size on the sample was about $1.5 \mu \mathrm{m}$. Due to the strong fluorescence the measuring time per accumulation had to be kept low, usually to $30 \mathrm{~s}$, but the number of accumulations could be set up to 60. Although the maximal measuring time could go up to $30 \mathrm{~min}$, the corresponding time of the experiment took several hours, due to the time needed to rotate the spectral grating. Thus, spectra with an acceptable signalto-noise $(\mathrm{S} / \mathrm{N})$ ratio could be obtained. Spectra were recorded in the range between 200 and $1800 \mathrm{~cm}^{-1}$.

\section{RESULTS AND DISCUSSION}

SEM and Raman Results. Prior to LA-ICPMS analysis, all the pigments and substrate samples were subjected to SEMEDX and Raman inspection, since these are nondestructive techniques. The composition of the substrates obtained by SEMEDX (15-20\% Ca, 15-20\% C, 60\% O) seems to suggest that these are mostly composed of calcite $\left(\mathrm{CaCO}_{3}\right)$, which is typical for that Spanish region. Regarding the pigment samples, high levels of $\mathrm{Ca}, \mathrm{C}$, and $\mathrm{O}$ were also detected, together with $\mathrm{Al}, \mathrm{Si}, \mathrm{Fe}$ (and sometimes $\mathrm{K}, \mathrm{Mg}$, and, more occasionally, P) at the low-percent level. As stated before, all the pigments are covered by accretions of different thickness that seem to consist mainly of calcite and, on occasions, of gypsum $\left(\mathrm{CaSO}_{4} \cdot 2 \mathrm{H}_{2} \mathrm{O}\right)$, which can be formed by reaction of atmospheric $\mathrm{SO}_{2}$ with the calcite substrate. ${ }^{32}$ The quantitative values obtained for $\mathrm{Ca}$ with this technique were particularly relevant since the signal of this element was selected

(32) Vandenabeele, P.; Lambert, K.; Matthys, S.; Schudel, W.; Bergmans, A.; Moens, L. Anal. Bioanal. Chem. 2005, 383, 707-712. 
as internal reference for LA-ICPMS quantification, as will be discussed later on.

Raman spectra confirmed the results mentioned above, allowing the unambiguous identification of calcite in the substrate and of calcite and gypsum in the superficial depositions. It was not always easy to identify the pigment responsible for the red color. The excessive fluorescence produced by these crystalline accretions prevented a proper Raman spectrum to be obtained using a $785 \mathrm{~nm}$ laser for some of the samples. ${ }^{33}$ Finally, by accumulation of spectra in order to improve the $\mathrm{S} / \mathrm{N}$ ratio, as described in the Experimental Section, Procedure for the Microcharacterization of the Pigments by Raman Spectroscopy, hematite $\left(\alpha-\mathrm{Fe}_{2} \mathrm{O}_{3}\right)$ could be detected in approximately $50 \%$ of the samples, so it can be considered as the main pigment. In addition to this, residues of organic compounds were also identified in some samples. However, it is always difficult to ascertain whether this is due to the use of organic substances as binders during the elaboration of the pigment or could be the result of some impurities incorporated into the painting later on. ${ }^{12}$

Optimization of LA-ICPMS Conditions. The main settings of the LA-ICPMS instrumentation were optimized during ablation of substrate samples, since the small size of the pigments did not allow the use of actual pigment samples for these measurements. The energy output of the laser was varied between 20 and 200 $\mathrm{mJ}$ (the maximum possible value for the system) in increments of $20 \mathrm{~mJ}$. No gain in sensitivity was obtained above $100 \mathrm{~mJ}$, but a final energy of $140 \mathrm{~mJ}$ (which corresponds to $1.7 \mathrm{~mJ}$ on the substrate) was selected for further work since it has been reported that ablating significantly above the threshold reduces possible fractionation effects in depth-profiling mode. ${ }^{34}$ The maximum repetition rate $(20 \mathrm{~Hz})$ was chosen for best sensitivity. A laser beam size of $60 \mu \mathrm{m}$ was considered appropriate. For this parameter, a compromise between achieving sufficient sensitivity while consuming minimum sample amounts had to be attained. The size of the pigment samples enables five replicates per sample to be carried out under these conditions, although in a few occasions only three replicates could be carried out.

The number of laser pulses per replicate was fixed at 600 , in order to be sure that the penetration into the sample would be deep enough to ablate the covering layer (depositions), the pigment layer (the most important one), and finally, even the substrate layer. The carrier gas (type and flow rate) was also optimized. Ablation under different flows between 0.1 and $1.5 \mathrm{~L}$ $\min ^{-1}$ of $\mathrm{Ar}$ and $\mathrm{Ar}+\mathrm{He}$ (mixed before the ablation chamber) was performed, and the results were compared. A value of $1.1 \mathrm{~L}$ $\min ^{-1} \mathrm{Ar}+0.4 \mathrm{~L} \mathrm{~min}^{-1} \mathrm{He}$ provided the best signal-to-blank ratio ${ }^{35}$ and resulted in an improvement in terms of sensitivity by a factor of 2 compared with that observed at the optimum Ar-only flow rate $\left(1.3 \mathrm{~L} \mathrm{~min}^{-1}\right)$. Finally, also the most important ICPMS instrument settings (including rf power) were optimized, and the optimum settings are summarized in Table 1.

No prior information on the elements that may allow establishing differences/similarities among the different pigments was

(33) Vandenabeele, P.; Bodé, S.; Alonso, A.; Moens, L. Spectrochim. Acta, Part A 2005, 61, 2349-2356.

(34) Mank, A. J. G.; Mason, P. R. D. J. Anal. At. Spectrom. 1999, 14, 11431153.

(35) Resano, M.; García Ruiz, E.; Mihucz, V. G.; Móricz, Á. M.; Záray, Gy.; Vanhaecke, F. J. Anal. At. Spectrom. 2007, 22, 1158-1162. available, and therefore, a nonrestrictive list, containing more than 50 target nuclides, was used. Next to metallic elements, also a few nonmetals (B, C, Cl, P, S, and Si) were chosen. Reliable monitoring of most of these elements by quadrupole ICPMS is not simple, but their signals could be used for diagnostics (e.g., to check whether it was likely that target signals suffered from spectral overlap in some particular cases). The most abundant isotope for every element was selected whenever possible, but in a significant number of cases, a less abundant nuclide was preferred in order to minimize potential spectral interferences. The list of nuclides finally monitored is shown in Table 1.

Strategy for LA-ICPMS Analysis of the Pigments. During LA-ICPMS measurements in depth-profiling mode, a transient signal is obtained as the laser beam penetrates into the material. Every single point obtained for every nuclide can be transformed into a concentration value, by appropriate calibration, and the evolution of the analyte contents as a function of depth can be monitored. An example of a typical LA-ICPMS signal is shown in Figure 2A. Obviously, the maximum Fe signal area should correspond with the ablation of the pigment layer, as illustrated in Figure 2A, and that is exactly the relevant part of the signal for our study.

This depth-profiling potential is an important advantage of LAICPMS when compared with other microanalytical techniques that are more established in archaeometry (such as PIXE, NAA, or $\mathrm{X}$-ray fluorescence) and can justify a broader use of this technique in this field in coming years. ${ }^{36}$ In particular, the flat-top beam profile of the $193 \mathrm{~nm}$ ArF excimer laser used in this work is ideal for this kind of application, as documented in previous works. ${ }^{37-39}$ In principle, by using an output energy significantly exceeding the threshold and a sufficiently wide laser beam diameter, it is possible to obtain representative compositional data throughout the process of ablation, as long as a value of 6 for the depth/ diameter ratio is not exceeded, ${ }^{34}$ although for this particular laser system it has been recommended not to exceed a depth/diameter ratio of 1.5 , in order to achieve uniform flat-bottomed craters. ${ }^{40}$ The examination of the craters obtained after ablation of the samples by SEM permitted us to estimate that the penetration depth obtained after firing 600 pulses varied between 21 and 27 $\mu \mathrm{m}$, corresponding to approximately $40 \mathrm{~nm}$ of penetration per pulse. The actual depth resolution is difficult to estimate without the help of matrix-matched material with perfectly established submicrometer-level layer thickness, but it would certainly not be as good as this value since other parameters (e.g., pulse mixing, signal tailing induced during aerosol transport, or data acquisition speed ${ }^{26,41}$ will have a negative influence. However, it may be safe to state that the resolution should be sufficient to establish differences at the micrometer level. The thickness of the Fe-rich layers was found to vary between 2 and $5 \mu \mathrm{m}$, which is in good

(36) Durrant, S. F.; Ward, N. I. J. Anal. At. Spectrom. 2005, 20, 821-829.

(37) Bleiner, D.; Plotnikov, A.; Vogt, C.; Wetzig, K.; Günther, D. Fresenius' J. Anal. Chem. 2000, 368, 221-226.

(38) Balcaen, L. I. L.; Lenaerts, J.; Moens, L.; Vanhaecke, F. J. Anal. At. Spectrom. 2005, 20, 417-423.

(39) Deconinck, I.; Latkoczy, C.; Günther, D.; Govaert, F.; Vanhaecke, F. J. Anal. At. Spectrom. 2006, 21, 279-287.

(40) Mason, P. R. D.; Mank, A. J. G. In Laser-Ablation-ICPMS in the Earth Sciences: Principles and Applications; Sylvester, P., Ed.; Mineralogical Association of Canada: Ottawa, Canada, 2001; pp 93-103.

(41) Plotnikov, A.; Vogt, C.; Hoffmann, V.; Täschner, C.; Wetzig, K. J. Anal. At. Spectrom. 2001, 16, 1290-1295. 
agreement with previous estimations by means of nuclear techniques for other Fe-based prehistoric pigments. ${ }^{12}$ Two SEM pictures of the craters obtained after sample ablation are shown in Figure 2B. As can be seem, regular, perfectly circular craters were always obtained, with the actual diameter varying between 58 and $65 \mu \mathrm{m}$, while the depth/diameter ratio never exceeded a value of 0.5 , which ensures meeting the previously mentioned requisites for representative depth-profiling analysis. The amount of sample consumed per replicate (600 laser pulses) was calculated to be approximately $180 \mathrm{ng}$, which represents a total mass of 900 ng (five replicates) per sample analyzed.

For the quantification of the elements monitored, there is no perfectly matrix-matched material available. Therefore, NIST SRM 610 and 612 glasses were used as standards. The selection of these materials is advantageous since they are homogeneous, and wellestablished reference values are available in the literature for most of the elements of interest. ${ }^{42,43}$ Recently, even for the S content, values have been reported. ${ }^{44}$ The only elements of the list for which no reference values are available (to the best of the authors' knowledge) are C, Hg, Ir, Ru, and Os. However, no Hg, Ir, Ru, or Os signals above the limit of detection (LOD) were detected for the samples, while $\mathrm{C}$ quantification is not expected to provide relevant fingerprinting information (and SEM values for this element were available anyway). Other elements that were practically not detected in any sample include $\mathrm{Au}, \mathrm{Ag}$, the rest of the platinum group metals, Be, and Re.

To correct for the differences in the ablation yields between the samples and the NIST SRM glass standards, the signal from ${ }^{44} \mathrm{Ca}^{+}$was used as internal reference, following the formula described in detail by Longerich et al. ${ }^{45} \mathrm{SEM}$ values for the $\mathrm{Ca}$ content in every sample were used in these calculations. This calibration strategy (use of NIST glasses and an internal reference of known concentration) has been reported to provide accurate results for any oxygen-rich matrix ${ }^{46}$ and, particularly, for carbonates, as is the case here. ${ }^{47}$ However, an additional experiment was carried out in order to evaluate the degree of accuracy that can be achieved in the analysis of rock art pigments by means of this strategy. The comparison of the results obtained with those provided by other techniques is not feasible in this case, as the techniques available in our labs lacked the sensitivity and/or depth resolution required for the task. Therefore, an Fe-based paint imitating those of prehistoric artists, but spiked with known amounts of some elements, was manufactured in-house, as described in the Procedure for Validation of LA-ICPMS Values in the Experimental Section.

The following elements ( $\mathrm{Al}, \mathrm{Ca}, \mathrm{Co}, \mathrm{Fe}, \mathrm{Mn}, \mathrm{Sn}, \mathrm{Ti}$, and $\mathrm{Pb}$ ) were selected for study in order to cover both a wide atomic mass range and a large concentration interval. These elements are usually present in the actual samples at concentrations ap-

(42) Pearce, N. J. G.; Perkins, W. T.; Westgate, J. A.; Gorton, M. P.; Jackson, S. E.; Neal, C. R.; Chenery, S. P. Geostand. Newsl. 1997, 21, 115-144.

(43) Sylvester, P. J.; Eggins, S. M. Geostand. Newsl. 1997, 21, 215-229.

(44) Guillong, M.; Latkoczy, C.; Günther, D.; Heinrich, C. A. ICP Inf. Newsl. 2007, 32, 1142.

(45) Longerich, H. P.; Jackson, S. E.; Günther, D. J. Anal. At. Spectrom. 1996 , 11, 899-904.

(46) Heinrich, C. A.; Pettke, T.; Halter, W. E.; Aigner-Torres, M.; Audétat, A.; Günther, D.; Hattendorf, B.; Bleiner, D.; Guillong, M.; Horn, I. Geochim. Cosmochim. Acta 2003, 67, 3473-3496.

(47) Putten, E. V.; Dehairs, F.; André, L.; Baeyens, W. Anal. Chim. Acta 1999, $378,261-272$.

\section{Table 2. Comparison of the Results Obtained for Analysis of an Fe-Based Paint Manufactured In-House by Means of Digestion and Subsequent Analysis via PN-ICPMS Analysis and by Means of Painting It onto a Rock Substrate and Subsequent LA-ICPMS Analysis of the Pigment Layera}

$\begin{array}{cccc}\text { analyte } & \begin{array}{c}\text { theor value } \\ \left(\mu \mathrm{g} \mathrm{g}^{-1}\right)\end{array} & \begin{array}{c}\text { solution ICPMS } \\ \left(\mu \mathrm{g} \mathrm{g}^{-1}\right)\end{array} & \begin{array}{c}\text { LA-ICPMS } \\ \left(\mu \mathrm{g} \mathrm{g}^{-1}\right)\end{array} \\ \mathrm{Al} & 67700 & 64000 \pm 600 & 61600 \pm 3100 \\ \mathrm{Ti} & 285 & 278 \pm 15 & 290 \pm 44 \\ \mathrm{Fe} & 59700 & 53700 \pm 3100 & 57900 \pm 7200 \\ \mathrm{Mn} & 210 & 200 \pm 11 & 205 \pm 44 \\ \mathrm{Co} & 61.5 & 59.0 \pm 2.1 & 49.8 \pm 13.3 \\ \mathrm{Sn} & 55.4 & 49.7 \pm 3.8 & 56.6 \pm 6.6 \\ \mathrm{~Pb} & 75.0 & 72.3 \pm 4.8 & 61.2 \pm 11.9\end{array}$

$a$ The theoretical value, calculated considering the total mass of every compound added in the production of the paint, is also indicated. Uncertainties are provided as $95 \%$ confidence intervals.

proximately ranging from $0.001 \%$ to $10 \%$. For the production of this Fe pigment "validation sample", the analyte amounts were added accordingly. This material was deposited onto a calciterich substrate and dried. Subsequent LA-ICPMS analysis of this sample was carried out, and the results were compared with those achieved after digestion of the paint by solution ICPMS analysis. The results obtained are shown in Table 2 . As can be seen, a good agreement was attained (the differences usually account for less than $15 \%$ and were not found to be statistically significant), indicating that the calibration procedure is capable of providing accurate values. Hence, the quantitative values obtained for the actual pigment samples could be considered as reliable.

It is relevant to further stress the behavior observed for the Ca signal during the ablation of the real pigment samples. In principle, one would expect a drop in the Ca signal when ablating through the Fe-rich layer, in comparison with the ablation of the superficial depositions and of the substrate, which consist mainly of Ca-rich minerals $\left(\mathrm{CaCO}_{3}\right.$ and $\left.\mathrm{CaSO}_{4}\right)$, as discussed in the Results and Discussion, SEM and Raman Results section. However, as shown in Figure 2A, this is not the case. Actually, the ${ }^{44} \mathrm{Ca}^{+}$signal is very stable throughout the ablation process. The slight decline in the signal intensity that can be appreciated is also observed during ablation of the very homogeneous NIST glasses, thus being related with a decrease in the amount of sample ablated as the crater gets deeper. ${ }^{34}$ This fact is in agreement with previous SEM-EDX results, reporting high contents of $\mathrm{Ca}$ throughout the sample including the pigment area, suggesting a weathering reaction between the substrate or accretions layers and the original pigment that occurred throughout time. ${ }^{4}$ The mechanism for the penetration of $\mathrm{Ca}$ in porous rocks has been described in various papers, and is in fact responsible for the flaking of many paintings, which is a serious reason for concern in art rock conservation. ${ }^{5,6}$ In any case, what it relevant to stress is that this phenomenon has two effects on the analytical quality of the LA-ICPMS data obtained. On the one hand, it makes the $\mathrm{Ca}$ content very constant throughout the pigment samples, not only across the surface but also in depth. This is very important for the use of this element as an internal reference, as it makes the Ca content as estimated by SEM (a technique that penetrates less than $1 \mu \mathrm{m}$ in the sample) still 


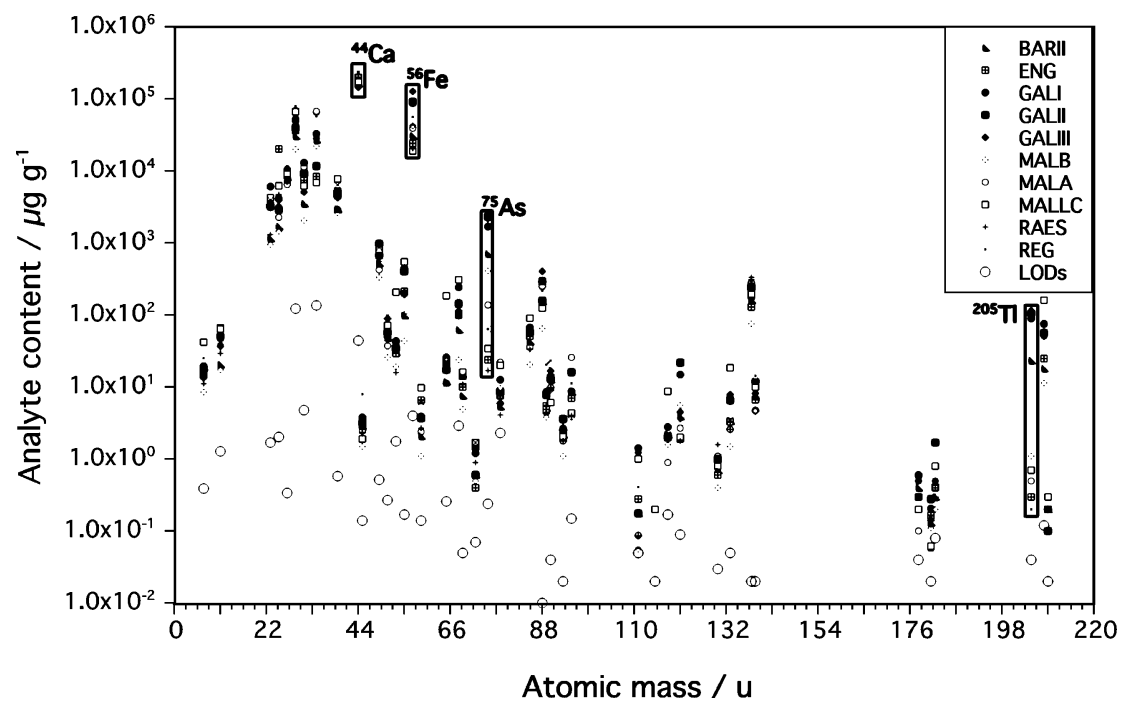

Figure 3. Average concentrations for every shelter sampled and limits of detections attained after LA-ICPMS analysis of the prehistoric pigments, as described in the Procedure for LA-ICPMS Analysis of the Pigments in the Experimental Section.

reliable when deeper depth-profiling analysis is performed. Moreover, this observation could be used to detect forgeries, since new paintings should not show the same homogeneous distribution of $\mathrm{Ca}$. On the other hand, there is a cause for concern too, since other elements could have migrated between the layers as well, therefore making the determination of the true contents of the analytes in the original pigment layer quite difficult.

LA-ICPMS Analysis of the Pigments and Comparison of the Different Shelters. Once the conditions were optimized, analysis of the samples was performed as described in Procedure for LA-ICPMS Analysis of the Pigments in the Experimental Section. Average values for every shelter are shown in Figure 3, as a summary. The values for the LODs are indicated as well. It can be said that, under our working conditions, LODs typically ranged between 10 and $100 \mathrm{ng} \mathrm{g}^{-1}$ for "heavy" elements $(\mathrm{u}>80)$ and between 100 and $1000 \mathrm{ng} \mathrm{g}^{-1}$ for light elements, with a few exceptions (elements affected by well-known interferences, such as $\mathrm{Si}, \mathrm{S}$, or $\mathrm{Ca}$, which are present at very high levels anyway). A total of 42 elements per sample were finally quantified.

For most elements, including $\mathrm{Fe}$, the contents may vary between different shelters by 1 order of magnitude, approximately. Calcium is a clear exception, as its concentration only varies between $14.5 \%$ and $23.6 \%$. This element is also the most homogenously distributed one within every sample (4-6\% RSD), which justifies its selection as internal reference. It can also be appreciated that $\mathrm{As}$ and $\mathrm{Tl}$ show much larger variations between the shelters (more than 2 and 3 orders of magnitude, respectively). Therefore, these elements may be particularly useful to establish different patterns.

In order to find meaningful differences or similarities among the samples, further data processing is needed for two reasons. On the one hand, the content of the Fe pigment added to every sample may be very different even if the same ore would have been used (e.g., different amount of extenders and/or binders could have been added), and therefore, the contents of the impurities associated with this pigment should vary consequently. On the other hand, as discussed in the previous sections, migrations of elements not associated with the Fe mineral but initially present in the substrate or in the superficial alterations may also have occurred. The indiscriminate use of the concentration of these elements would only hamper the establishment of patterns for any statistical technique.

Therefore, in order to determine which elements could have been truly related with the original pigments, the correlation between the content of $\mathrm{Fe}$ and the content of every other analyte was investigated in every sample. The corresponding coefficients of correlation were calculated using all of the replicates available per sample, and only six elements were observed to show a coefficient higher than 0.9 for at least $50 \%$ of the samples. These elements were $\mathrm{As}, \mathrm{Co}, \mathrm{Mo}, \mathrm{Sb}, \mathrm{Tl}$, and $\mathrm{Zr}$. Thus, subsequent analysis was restricted to these relevant elements only. Finally, the contents of these elements were normalized to the amount of Fe present. In this way, the analyte content was calculated per $1 \% \mathrm{Fe}$, thus correcting for the possible differences in the amount of Fe pigment actually added to each sample.

Hierarchical cluster analysis (using the weighted pair-group with arithmetic averaging method and Euclidean distances as the measure of similarity) of the data obtained was carried out, allowing us to extract some conclusions. The data was first standardized by means of the standard normal variate transformation, as described elsewhere. ${ }^{48,49}$ The results are shown in Figure 4 in the form of a dendrogram. Two large clusters can be clearly appreciated. The shelters from Gallinero (GALI, GALII, and GALIII), which are only a few meters away from each other, appeared together. All of the paintings analyzed from these shelters seem to belong to the same paint "pot". These samples show higher As $\left(\approx 2000 \mu \mathrm{g} \mathrm{g}^{-1}\right)$ and $\mathrm{Tl}\left(\approx 100 \mu \mathrm{g} \mathrm{g}^{-1}\right)$ levels and lower contents for the rest of the elements. The presence of $\mathrm{Tl}$ is significant, since this is not an element as ubiquitous as As and it is not expected to be present as such high levels in soil or clay. Thus, it seems to indicate that the origin of this Fe pigment was an actual mineral deposit, in which hematite may have been associated with pyrites or arsenopyrites, since $\mathrm{Tl}$ is a common impurity of these minerals. It is hard to identify the actual origin

(48) Barnes, R. J.; Dhanoa, M. S.; Lister, S. J. Appl. Spectrosc. 1989, 43, 772777.

(49) Resano, M.; Vanhaecke, F.; Hutsebaut, D.; De Corte, K.; Moens, L. J. Anal. At. Spectrom. 2003, 18, 1238-1242. 


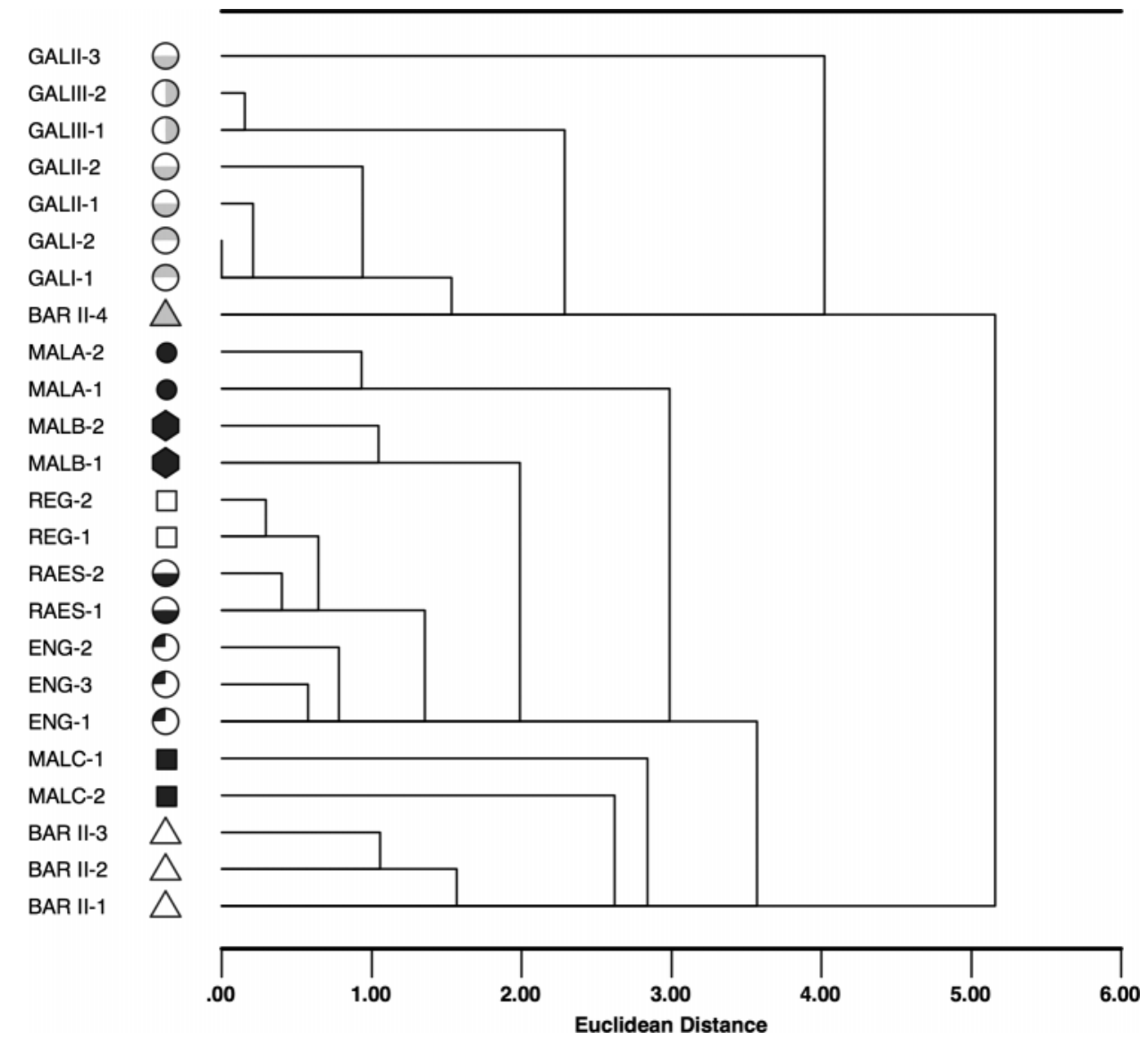

Figure 4. Dendrogram showing the hierarchical clustering of the results obtained upon LA-ICPMS analysis of the prehistoric pigments, selection of the elements correlated with $\mathrm{Fe}$ (As, $\mathrm{Co}, \mathrm{Mo}, \mathrm{Sb}, \mathrm{TI}$, and $\mathrm{Zr}$ ), and normalization of their contents to the percent of $\mathrm{Fe}$.

of this pigment because Spain is rich in Fe deposits. Moreover, in the post-Paleolithic period, pigment trade can be considered as feasible, as suggested by Chalmin et al. ${ }^{50}$ In any case, further work will be conduced to try to identify this deposit.

It is also remarkable that one sample from the Barfaluy shelter (BAR II-4) also clusters together with Gallinero samples. The Barfaluy shelter is located only 100 meters away from the Gallinero shelters. These results suggest that one of the Barfaluy figures was painted using the same pot as that of the Gallinero paintings. The rest of the Barfaluy samples are clearly different and similar among them, thus probably all originating from another single paint. A more detailed investigation of this shelter may help in establishing how many different paint pots were used for creating all of the figures found in it, although it has to be considered whether a more extensive sampling can be authorized.

For the remaining samples, it can be seen that samples from the same shelter always cluster well together, indicating the capabilities of the technique used for fingerprinting. The shelters from Mallata and Tozal de Mallata (MALA, MALB, and MALC) are separated by less than 200 meters from one another. However, although MALA and MALB samples are very similar, those originating from MALC show a significantly different chemical composition (characterized by higher $\mathrm{Co}$ and $\mathrm{V}$ levels and a lower As content). On the other hand, La Raja E (RAES) and Coveta de l'Engardaixo (ENG) are the shelters most separated from the

(50) Chalmin, E.; Vignaud, C.; Salomon, H.; Farges, F.; Susini, J.; Menu, M. Appl. Phys. A 2006, 83, 213-218. relatively small area (less than $10 \mathrm{~km}$ distance) where the rest of them are placed. La Raja E is located approximately $38 \mathrm{~km}$ west and Coveta de l'Engardaixo is located approximately $20 \mathrm{~km}$ east. In spite of this, ENG, RAES, and REG samples show a similar chemical composition, forming a subcluster, indicating the use of comparable paint pots. Certainly, the total distance between these shelters is still short enough, so it seems feasible that the same group of people could have produced the paintings found in them.

\section{CONCLUSIONS}

It is obvious that investigation of prehistoric paintings is a complex task, and meaningful archaeological information would only be obtained by combining different analytical techniques. However, LA-ICPMS can be a very interesting addition to the arsenal of techniques currently in use for this purpose. Unlike other elemental techniques, LA-ICPMS is capable of providing spatially resolved (both laterally and in depth) quantitative multielement information for analytes present in a wide concentration range (from microgram per gram to $10 \%$ level). In addition to the intrinsic value of these results, this information, after suitable data processing, was demonstrated to be very useful for fingerprinting purposes.

Further use of this technique may assist in resolving specific archaeological questions in the investigation of painting superimpositions or in the determination of the number of different paint pots used in a large shelter, which can help to establish chronologies among the figures. Future work in that direction 
will be conducted, in connection with the examination of some important shelters found in Teruel (Spain).

\section{ACKNOWLEDGMENT}

The authors thank the Spanish Ministry of Education and Science (Project CTQ2006-03649/BQU), the University of Zaragoza (Ibercaja Project 230-121), and the Government of Aragón, (DGA Proyecto Multidisciplinar PM055/2006 and PM013/2007) for funding. The help and time of Niko Thoen during the Raman measurements is greatly appreciated. M.R. acknowledges the Programa Nacional de Ayudas para la Movilidad de Profesores de Universidad (MEC) for his grant. P.V. acknowledges the financial support of the Interuniversity Attraction Poles Programme-Belgian State-Belgian Science Policy.

Received for review June 19, 2007. Accepted September 18, 2007.

AC0712953 